\title{
The level of carbonation of a sugar-sweetened beverage preload affects satiety and short-term energy and food intakes
}

\author{
S. Anne Moorhead ${ }^{1}$, M. Barbara E. Livingstone ${ }^{1}$, Adrian Dunne ${ }^{2}$ and Robert W. Welch ${ }^{1 *}$ \\ ${ }^{1}$ Northern Ireland Centre for Food and Health, School of Biomedical Sciences, University of Ulster, Coleraine, UK \\ ${ }^{2}$ School of Mathematical Sciences, University College Dublin, Belfield, Dublin, Republic of Ireland
}

(Received 26 July 2007 - Revised 23 October 2007 - Accepted 24 October 2007 - First published online 17 December 2007)

The consumption of sugar-sweetened beverages is associated with increased incidence of overweight and obesity, and a factor underlying this putative link could be the relatively low levels of satiety that may be induced by these beverages. Although many sugar-sweetened beverages are carbonated, little attention has been given to the potential effects of level of carbonation on satiety and subsequent intakes. We hypothesized that increasing the level of carbonation in a sugar-sweetened beverage would increase satiety and decrease intakes in the short term. Using a randomized, within-subject cross-over design, thirty non-obese subjects (fifteen women, fifteen men) participated on three occasions, 1 week apart. Following a standard breakfast, subjects consumed a beverage preload $10 \mathrm{~min}$ before consuming a lunch ad libitum. Preloads were the same sugarsweetened beverage $(400 \mathrm{ml}, 639 \mathrm{~kJ})$ with three levels of carbonation, which were low (1.7 volumes), medium (2.5 volumes) and high (3.7 volumes). Satiety was assessed using visual analogue scales and intakes were measured at the lunch and for the rest of the day. Compared with the beverage with low carbonation, consumption of the beverages with medium and high carbonation led to significantly $(P<0.05)$ higher satiety until lunch, when intakes of food and energy were significantly $(P<0 \cdot 05)$ lower. There were no significant effects on satiety following lunch or on intakes for the rest of the day. This short-term study suggests that the level of carbonation may need to be taken into account when assessing potential effects of beverages on satiety and intake.

Sugar-sweetened beverages: Carbonation: Satiety: Energy intake

Although inconclusive, many studies support links between consumption of sugar-sweetened beverages and increases in energy intake, weight gain and obesity ${ }^{(1-3)}$. The mechanism(s) underlying such links are unclear ${ }^{(1,3,4)}$, but it has been suggested that increased energy intake occurs because sugarsweetened beverages induce comparatively low satiety and thus subsequent compensation in intake is less complete with than with solid foods ${ }^{(2)}$. However, the term 'sugar-sweetened beverages' comprises a wide range of products including sodas, fruit drinks and squashes and includes both carbonated and non-carbonated beverages. Some previous experimental studies that compared the effects of different beverages on satiety and intake have included both carbonated and non-carbonated beverages ${ }^{(5-7)}$, but few previous studies have evaluated the potential effects of carbonation itself.

Conventionally, beverage carbonation is expressed as vol. $\mathrm{CO}_{2}$ per vol. liquid. The level of carbonation in commercial beverages varies from low (about 1 vol. $\mathrm{CO}_{2}$ ) in fruit drinks to medium (2-3 vol. $\left.\mathrm{CO}_{2}\right)$ in colas and alcohol-containing beverages to high (approximately $4.5 \mathrm{vol} . \mathrm{CO}_{2}$ ) in other drinks such as tonic water, which are consumed as mixers with alcoholic beverages ${ }^{(8)}$. Thus, the volume of dissolved $\mathrm{CO}_{2}$ may far exceed the volume of liquid. The fate of ingested dissolved $\mathrm{CO}_{2}$ is unclear. However, when $300 \mathrm{ml}$ carbonated
(2.5 vol. $\mathrm{CO}_{2}$ ) or still mineral water was consumed by women and men just after a solid-liquid meal, $\mathrm{CO}_{2}$ was liberated from the carbonated water in the stomach, where it led to increased distension and a greater retention of meal components during the postprandial lag phase ${ }^{(9)}$. Although there were no significant differences in the rate of total gastric emptying or in postprandial satiety, these results show that $\mathrm{CO}_{2}$ dissolved in beverages can impact on gastric function when consumed after a meal. In a study in which an electrolyte beverage with $0,1 \cdot 1,2.3$ or 3.0 vol. $\mathrm{CO}_{2}$ was provided to women and men for consumption ad libitum after exercise, intakes of the beverage decreased significantly and progressively as carbonation level increased from $1 \cdot 1$ to $3 \cdot 0$ vol. ${ }^{(10)}$. Furthermore, when gas (air) was incorporated into a beverage preload, increasing the volume from $300 \mathrm{ml}$ to $600 \mathrm{ml}$, satiety was increased and intakes at lunch $15 \mathrm{~min}$ later decreased significantly ${ }^{(11)}$. Overall these results suggest that the release of dissolved $\mathrm{CO}_{2}$ from carbonated beverages in the stomach may influence satiety and subsequent intakes.

$\mathrm{CO}_{2}$ yields a weakly acid solution. A range of acids can decrease gastric emptying rate and the addition of acids to foodstuffs has been shown to increase satiety ${ }^{(12-14)}$. Furthermore, a carbonated drink with high titratable acidity decreased food intakes when $473 \mathrm{ml}$ portions were ingested $20 \mathrm{~min}$

Abbreviation: VAS, visual analogue scale.

* Corresponding author: Robert W. Welch, fax +44 287032 4965, email rw.welch@ulster.ac.uk 
before a meal ${ }^{(15)}$. Thus, in addition to potential effects of released $\mathrm{CO}_{2}$ on gastric volume and function, increased carbonation may influence satiety and intake by impacting on gastric acidity.

We hypothesized that the level of carbonation in a commercial soft beverage, consumed as a preload, would enhance satiety and decrease intakes in non-obese subjects and that this may be due to volume effects of liberated $\mathrm{CO}_{2}$ and/or to effects of $\mathrm{CO}_{2}$ on gastric $\mathrm{pH}$. Men and women differ in eating behaviour ${ }^{(16)}$ and there are reported gender differences in postprandial satiation and satiety responses ${ }^{(17,18)}$. Furthermore, although data are inconclusive, gastric emptying rates for both solids and liquids are generally found to be slower in women than in men ${ }^{(19-22)}$. Thus, potential gender differences were also assessed.

\section{Experimental methods}

\section{Subjects}

Healthy subjects (fifteen men, fifteen women) were recruited from the staff and student population at the University of Ulster. Inclusion criteria were: aged 20-40 years; BMI $20-29.9 \mathrm{~kg} / \mathrm{m}^{2}$; non-smokers; liking for all the foods to be served in the study; no known food allergies or restrictions; not on a specific diet; not taking any medications known to affect appetite; for women, not taking oral contraceptives, regularly menstruating and not pregnant or lactating. At enrolment, subjects completed the Dutch Eating Behaviour Questionnaire $^{(23)}$, which gives a measure of restrained, emotional and external eating, and weight and height were measured to calculate BMI. On each study day, women reported their current stage (week 1, 2, 3, 4) in the menstrual cycle. The study was approved by the Research Ethical Committee of the University of Ulster and all subjects gave written, informed consent.

\section{Design and procedures}

The present study used a randomized, within-subject crossover design, with three beverage preload conditions. Subjects were randomly divided into six equal-sized groups counterbalanced for gender using a computerized numbered system and each group was randomly assigned to receive the three preloads in one of the six possible orders. Each group was studied on the same day of the week with 1-week intervals between cross-over. All meals were served in the metabolic suite of the university and the subjects were free to leave after each meal to continue normal activities.

The subjects were asked to fast from 22.00 hours the previous day and to refrain from strenuous activity on each study day. On arrival at 09.00 hours, compliance was confirmed and the subjects consumed the same standard breakfast, which provided $25 \%$ estimated energy intakes that were calculated as 1.4 times estimated $\mathrm{BMR}^{(24)}$. Following this, subjects were instructed not to eat during the morning and to drink only non-carbonated water $(2 \times 500 \mathrm{ml}$ bottles $)$, which could be consumed ad libitum. At 12.00 hours, bottles were returned for assessing intakes and baseline visual analogue scales (VAS) were completed. Following this, beverage preloads $(400 \mathrm{ml})$ were served in $100 \mathrm{ml}$ portions at $2 \mathrm{~min}$ intervals and subjects were asked to drink each portion completely within the $2 \mathrm{~min}$ period. Subjects completed VAS after the final beverage portion and after a further $10 \mathrm{~min}$, just before being served with a lunch meal to be consumed ad libitum.

Subjects completed VAS after the ad libitum lunch meal and at $45 \mathrm{~min}$ intervals for $225 \mathrm{~min}$, until 16.30 hours, during which time they were instructed to consume only the non-carbonated water provided $(2 \times 500 \mathrm{ml})$. Preset timers were provided to remind the subjects to complete VAS. At 16.30 hours, bottles were returned for assessment of water intakes and subjects were given food diaries to complete (description of food or beverage, brand name if appropriate, estimated portions and leftovers) for the remainder of the day, during which they were permitted to eat and drink as they wished.

\section{Preloads and meals}

Breakfasts, which provided $25 \%$ of each subject's estimated energy intake, consisted of ready-to-eat cereal with milk, toast with butter or margarine and preserve, served with coffee or tea (with milk and sugar if desired). Subjects made breakfast choices before the commencement of the study and the same breakfast, both in terms of foods and amounts, was consumed on each occasion.

The preloads were bottled beverages based on a commercial formulation and supplied by Maine Soft Drinks Ltd. (Ballymoney, UK), who were commissioned to produce beverages with three levels of carbonation: none; medium; high. On receipt, the $\mathrm{CO}_{2}$ contents of the beverages were measured (see later) and found to be 338,494 and $728 \mathrm{mg} \mathrm{CO} 2$ per $100 \mathrm{ml}$, respectively, which are equivalent to $1.7,2.5$ and 3.7 vol. $\mathrm{CO}_{2}$ per vol. liquid, respectively. Although the level of $\mathrm{CO}_{2}$ at the lowest level was higher than expected, there was little effervescence when poured. The beverages are thus referred to as low, medium and high carbonation. Beverage ingredients were water, orange juice, sucrose, citric acid and ascorbic acid and each $400 \mathrm{ml}$ preload provided $639 \mathrm{~kJ}$ energy, $0.4 \mathrm{~g}$ protein and $39.5 \mathrm{~g}$ carbohydrate (supplier's data). Beverages were supplied in $730 \mathrm{ml}$ bottles and stored at $4^{\circ} \mathrm{C}$ until required. On each study day, the $100 \mathrm{ml}$ portions of the beverages were poured, kept at $4^{\circ} \mathrm{C}$ and served within $10 \mathrm{~min}$.

The complete two-course lunch meal for ad libitum consumption was provided on a tray. Subjects were instructed to eat until comfortably full. The first course was cottage pie, which consisted of lean minced beef, onion and carrot in gravy covered with mashed potato and topped with cheese, served hot. The cottage pie was made in bulk in a catering kitchen, according to a standardized recipe and served in $1200 \mathrm{~g}$ portions. The second course was canned peaches $(200 \mathrm{~g})$ and canned pears $(200 \mathrm{~g})$ served with a separate bowl of cream $(100 \mathrm{~g})$. The only beverage supplied was bottled non-carbonated water $(2 \times 500 \mathrm{ml}$; Ballygowan Ltd., Newcastle West, Ireland). The total energy and nutrient content of the meal, which was calculated using manufacturers' data where available or data from food tables ${ }^{(25)}$, was $8944 \mathrm{~kJ}, 103.8 \mathrm{~g}$ protein, $135.2 \mathrm{~g}$ fat, $136.0 \mathrm{~g}$ carbohydrate and $12.1 \mathrm{~g}$ dietary fibre. 
Visual analogue scale assessments

Satiety and hedonic and sensory factors were assessed using VAS by the pen and paper method ${ }^{(26)}$. Each scale consisted of a plain $100 \mathrm{~mm}$ horizontal line preceded by a question and with anchors at each end. Subjects were asked to put a single vertical mark at the appropriate point to describe their feelings. The questions and left and right anchors were: 'How hungry do you feel?' (hunger), 'not hungry at all', 'as hungry as I have ever felt'; 'How full do you feel?' (fullness), 'not full at all', 'as full as I have ever felt'; 'How strong is your desire to eat?' (desireto-eat), 'very weak', 'very strong'; 'How much food do you think you could eat?' (prospective consumption), 'nothing at all', 'a large amount'; 'How thirsty are you?' (thirst), 'not thirsty at all', 'as thirsty as I have ever felt'; 'How comfortable do you feel?' (comfort), 'not comfortable at all', 'as comfortable as I have ever felt'. Immediately after the preload, subjects also completed VAS with the questions and anchors: 'What do you think about the total amount of the beverage you have just consumed?' (size), 'extremely small', 'extremely large'; 'How effervescent (fizzy) was the beverage?' (effervescence), 'not effervescent at all', 'extremely effervescent'; 'How sweet was the beverage?' (sweetness), 'not sweet at all', 'extremely sweet'; 'How strong was the flavour of the beverage?' (flavour), 'not strong at all', 'extremely strong'; 'Overall, how pleasant was the beverage?' (pleasantness), 'not at all pleasant', 'extremely pleasant'.

\section{Intake assessments}

After the ad libitum lunch meal, individual leftovers were weighed and intakes were calculated by difference. Data from the food diaries for the rest of the day were converted to weights using label information or from standard portion sizes ${ }^{(27)}$. Energy, macronutrient and fibre intakes from the lunch meal consumed ad libitum and from the food diaries were calculated using a dietary analysis program (Wisp version 2.0; Tinuviel Software, Warrington, UK). The amount of water in food and drink was calculated from food table data ${ }^{(25)}$ using Microsoft ${ }^{\circledR}$ Excel (version 2000; Microsoft Corporation).

\section{Laboratory evaluations}

Prior to all analyses, bottles were stored at $4{ }^{\circ} \mathrm{C}$, poured in the same way as the preload servings and analysed within $10 \mathrm{~min}$. The $\mathrm{CO}_{2}$ contents of the beverages were measured in duplicate using the Association of Official Analytical Chemists method for wines ${ }^{(28)}$. Beverage $\mathrm{pH}$ was measured using a $\mathrm{pH}$ meter (Corning M20; Corning, Sudbury, UK). Buffering capacities were measured by monitoring $\mathrm{pH}$ changes, as duplicate $100 \mathrm{ml}$ samples of the three beverages were titrated with $2 \mathrm{M}-\mathrm{HCl}$ to $\mathrm{pH} 2$ and with $2 \mathrm{M}-\mathrm{NaOH}$ to $\mathrm{pH} 10$.

\section{Statistical analysis}

Data were analysed using SAS version 8.0 (SAS Institute Inc., Cary, NC, USA). Analysis of variance was performed with a mixed effect model for a three period cross-over design, which compared the three conditions (low, medium and high carbonation) ${ }^{(29)}$. The model contained condition, gender, period and carry-over, a random subject effect and a random error. The fixed effects were condition, gender, period and carry-over. The condition effect refers to differences in the mean responses of the variables (VAS and timings, the weight of food and drink, and energy, macronutrient, fibre and water intakes) between the three conditions, while the period effect refers to differences in the mean responses due to systematic differences between the condition periods. Analysis showed that the effects of carry-over and period were non-significant. Thus, assuming no carry-over, an $F$ ratio test was conducted for comparisons of significant effects of each variable between conditions ${ }^{(29)}$. To compare specific conditions, linear contrasts were used to examine differences between means. Although there were significant differences between gender, the gender by condition interactions were all non-significant. Results were considered significant at $P<0.05$ and values are reported as means and standard deviations with ranges where appropriate.

\section{Results}

\section{Subjects}

All subjects completed the study and subject characteristics are presented in Table 1. From the Dutch Eating Behaviour Questionnaire ${ }^{(23)}$, subjects scored the following: for restrained eating 2.08 (SD 0.86) (1.00-3.78); emotional eating 1.98 (SD 0.67) (1.17-3.75); external eating, 3.29 (SD 0.68) (1.92-4.25). There are no accepted cut-off points for these factors but Green and Blundell considered that a score $>3$ indicated restrained eaters ${ }^{(30)}$. Therefore, on this basis, four subjects scored $>3$ but $<4$ for restrained eating. The reported weeks of the women's menstrual cycle, which were 2.50 (SD 1.05) $(1-4), 2 \cdot 35$ (SD 1.18) (1-4) and 2.60 (SD 1.09) (1-4), respectively, for the low, medium and high carbonation conditions, were not significantly different. There were no significant differences in ad libitum water intake between meals.

\section{Hedonic and sensory ratings of the preloads}

All subjects completely consumed the preloads. The three beverages did not differ significantly in reported sweetness, flavour or pleasantness and there were no significant differences between women and men for these sensory and hedonic responses (Table 2). Overall, there were no significant differences between the three beverages for size ratings. However, compared with the men, the women rated the beverages to be significantly larger. There were significant differences between the three beverages in reported effervescence, which increased from low, to medium, to high carbonation. Overall, the men found the beverages to be significantly more effervescent than the women (Table 2).

Table 1. Subject characteristics*

(Mean values, ranges and standard deviations)

\begin{tabular}{|c|c|c|c|c|c|c|}
\hline & \multicolumn{3}{|c|}{ Women (n 15) } & \multicolumn{3}{|c|}{ Men (n 15) } \\
\hline & Mean & Range & SD & Mean & Range & SD \\
\hline Age (years) & $22 \cdot 0$ & $19-25$ & 1.88 & 22.5 & $18-28$ & 3.02 \\
\hline Weight (kg) & $63 \cdot 2$ & $50 \cdot 0-76 \cdot 2$ & $2 \cdot 14$ & $73 \cdot 6$ & $58 \cdot 9-90 \cdot 4$ & $2 \cdot 10$ \\
\hline BMI $\left(\mathrm{kg} / \mathrm{m}^{2}\right)$ & 23.5 & $20 \cdot 0-27.9$ & $2 \cdot 73$ & $24 \cdot 1$ & $20.7-29.8$ & $2 \cdot 61$ \\
\hline
\end{tabular}

${ }^{*}$ For details of subjects and procedures, see Experimental methods. 
Table 2. Sensory and hedonic responses to the beverage preloads for women and menł

(Mean values and standard deviations)

\begin{tabular}{|c|c|c|c|c|c|c|c|c|c|c|c|c|c|}
\hline & \multicolumn{12}{|c|}{ Level of carbonation } & \multirow[b]{4}{*}{ Women $v$. men $P$} \\
\hline & \multicolumn{4}{|c|}{ Low } & \multicolumn{4}{|c|}{ Medium } & \multicolumn{4}{|c|}{ High } & \\
\hline & \multicolumn{2}{|c|}{ Women ( $n$ 15) } & \multicolumn{2}{|c|}{ Men (n 15) } & \multicolumn{2}{|c|}{ Women $(n 15)$} & \multicolumn{2}{|c|}{ Men (n 15) } & \multicolumn{2}{|c|}{ Women (n 15) } & \multicolumn{2}{|c|}{ Men (n 15) } & \\
\hline & Mean & SD & Mean & SD & Mean & SD & Mean & SD & Mean & SD & Mean & SD & \\
\hline Size* & $71^{\mathrm{a}}$ & 20 & $61^{A}$ & 19 & $73^{a}$ & 18 & $60^{A}$ & 13 & $76^{a}$ & 16 & $65^{\mathrm{A}}$ & 21 & 0.036 \\
\hline Effervescence & $7^{a}$ & 9 & $12^{\mathrm{A}}$ & 16 & $49^{b}$ & 30 & $65^{\mathrm{B}}$ & 16 & $62^{c}$ & 31 & $75^{\mathrm{C}}$ & 22 & 0.048 \\
\hline Flavour† & $74^{\mathrm{a}}$ & 19 & $72^{\mathrm{A}}$ & 23 & $69^{a}$ & 30 & $71^{\mathrm{A}}$ & 24 & $73^{a}$ & 20 & $73^{A}$ & 21 & 0.488 \\
\hline Pleasantness $†$ & $35^{\mathrm{a}}$ & 23 & $46^{A}$ & 27 & $39^{a}$ & 22 & $48^{\mathrm{A}}$ & 15 & $34^{a}$ & 20 & $37^{\mathrm{A}}$ & 18 & 0.386 \\
\hline
\end{tabular}

a, b, c, A, B, C Mean values within a row with unlike superscripts were significantly different $(P<0.05)$; lower case for women; upper case for men $(F$ ratio test).

*Anchors for size were: on the left (0) 'extremely small'; on the right (100) 'extremely large'.

† Anchors for effervescence, sweetness, flavour and pleasantness were: on the left (0) 'not __ at all'; on the right (100) 'extremely __ '

$\ddagger$ For details of subjects and procedures, see Experimental methods.

\section{Satiety, thirst and comfort ratings}

Compared with baseline, consumption of the preloads led to significant changes in perceived hunger, fullness, desire-toeat and thirst in the period before the lunch for both men and women (Figs. 1 and 2). There were significant differences between preloads and the medium and high carbonation preloads led to consistently and significantly lower hunger
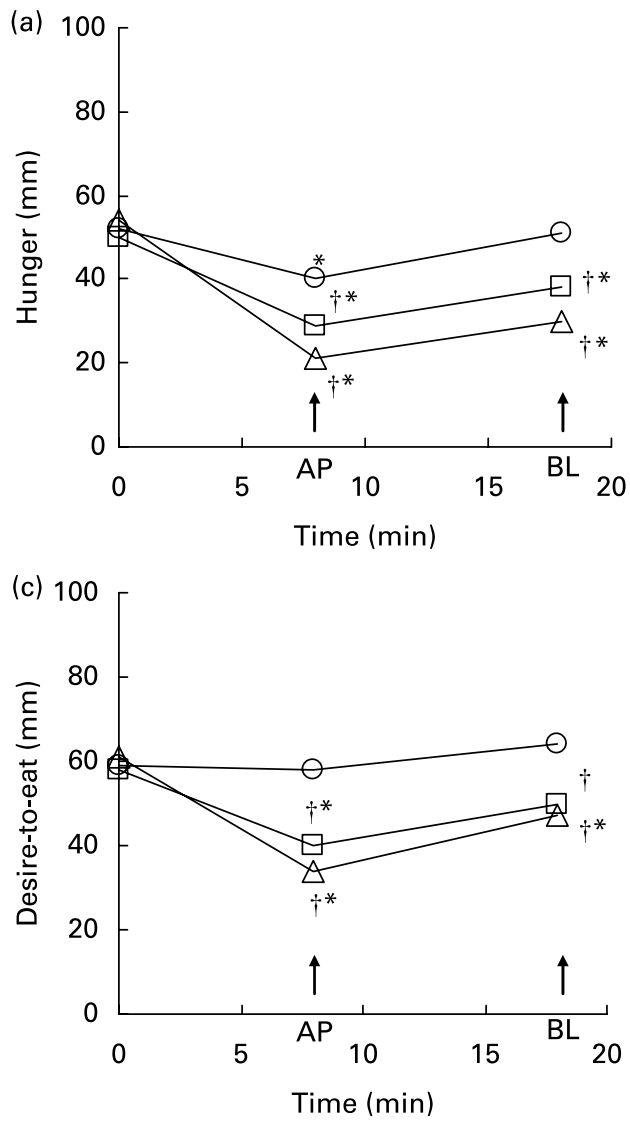

and desire-to-eat scores, and higher fullness scores, than the low carbonation preload. There were no significant differences between preloads for thirst ratings (Figs. 1 and 2). Ratings of prospective consumption followed the same pattern as desireto-eat, and comfort ratings did not differ significantly from baseline or between preloads (data not shown). There were no significant differences between the three beverages for ratings of hunger, fullness, desire-to-eat, prospective
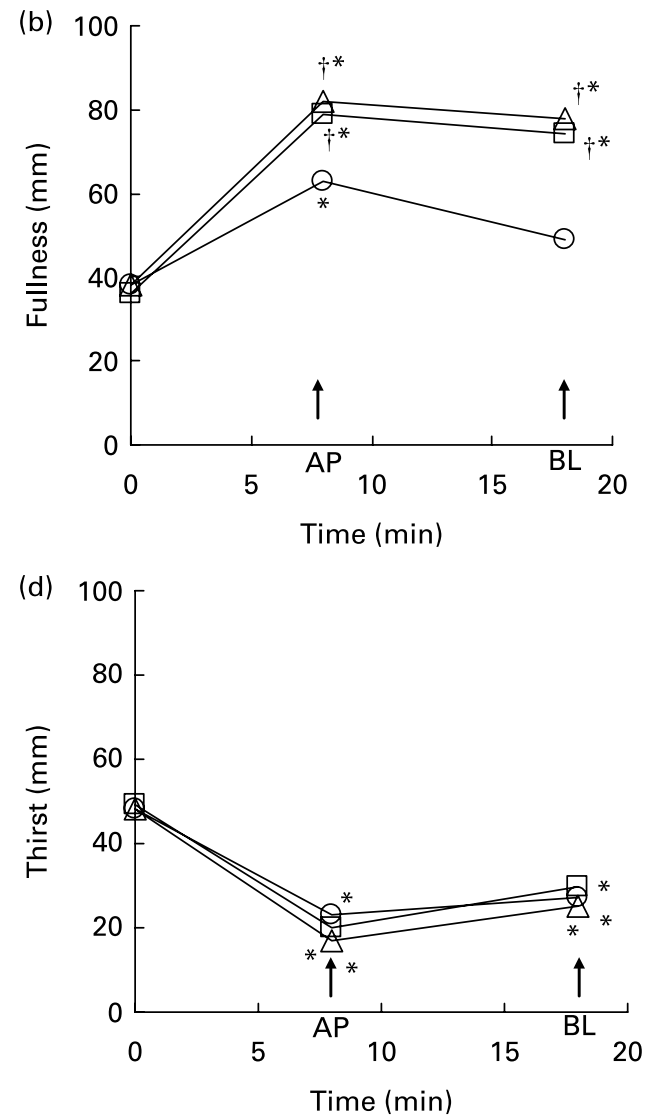

Fig. 1. Mean visual analogue scale ratings of (a) hunger, (b) fullness, (c) desire-to-eat and (d) thirst from before the carbonated beverage preload until 18 min post consumption for women $(n 15)$. $\bigcirc$, low carbonation; $\square$, medium carbonation; $\Delta$, high carbonation; AP, after preload; BL, before lunch. ${ }^{*}$ Significantly different from baseline $(P<0.05 ; F$ ratio tests). †Significantly different from low carbonation $(P<0.05 ; F$ ratio tests). For details of subjects and procedures, see Experimental methods. 

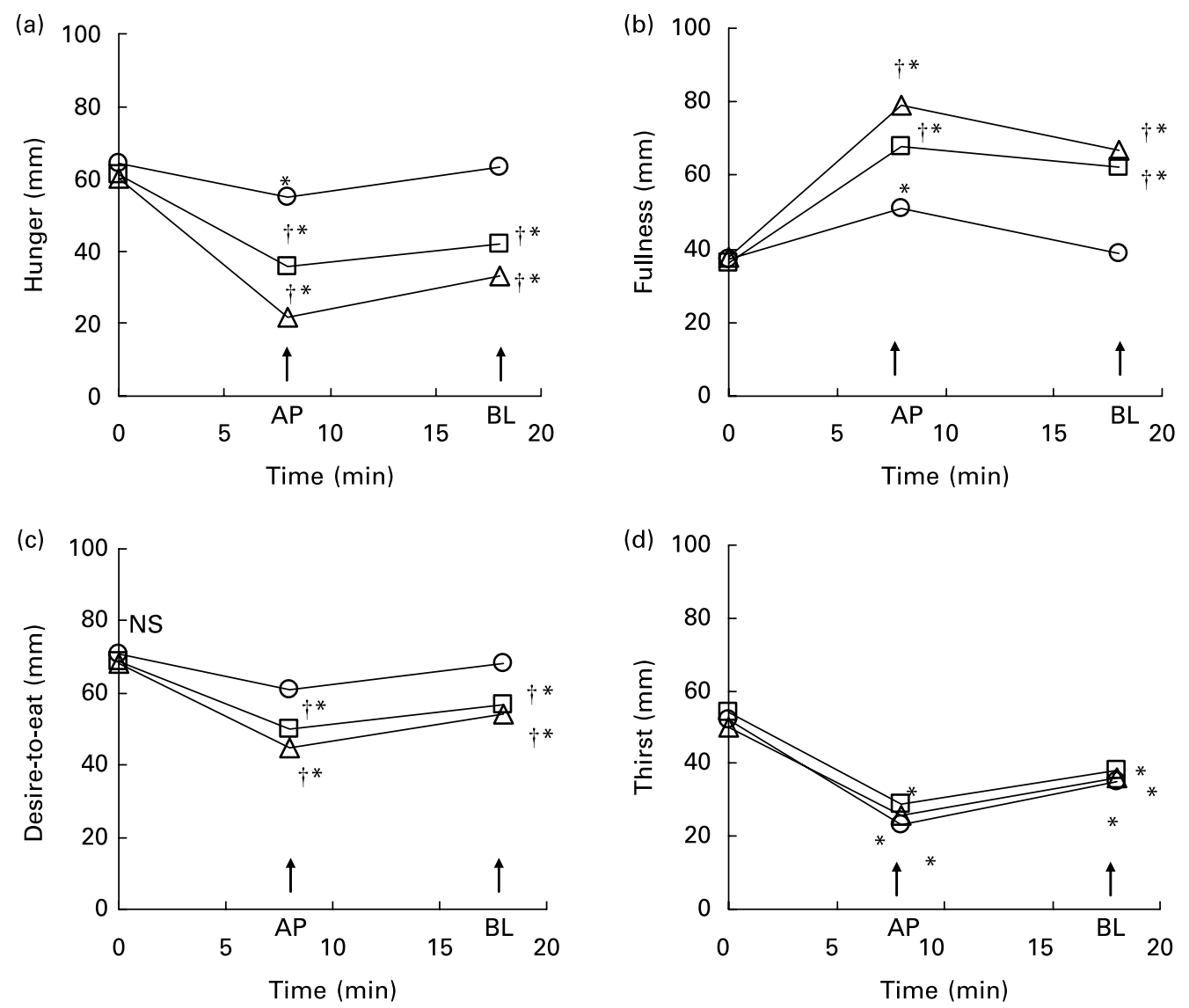

Fig. 2. Mean visual analogue scale ratings of (a) hunger, (b) fullness, (c) desire-to-eat and (d) thirst from before the carbonated beverage preload until 18 min post consumption for men $(n 15)$. $\bigcirc$, low carbonation; $\square$, medium carbonation; $\Delta$, high carbonation; AP, after preload; BL, before lunch. ${ }^{\star}$ Significantly different from baseline $(P<0.05 ; F$ ratio tests). †Significantly different from low carbonation $(P<0.05 ; F$ ratio tests). For details of subjects and procedures, see Experimental methods.

consumption, comfort or thirst from after the ad libitum lunch meal for $225 \mathrm{~min}$ (data not shown).

\section{Intakes at lunch and for the rest of the day}

No subjects completely consumed either course of the $a d$ libitum lunch meal. Overall, there were significant differences between preload carbonation level $(P=0.027)$ and between women and men $(P=0.039)$ for intakes of total energy and weight of food at the ad libitum lunch. Furthermore, intakes of total energy and weight of food decreased consistently with increasing level of carbonation for both women and men (Fig. 3). Compared with the low carbonation preload, energy intakes following the high carbonation preload were $739 \mathrm{~kJ}(19 \%)$ lower in women and $710 \mathrm{~kJ}(15 \%)$ lower in men, and food intakes were lower by $221 \mathrm{~g}(28 \%)$ in women and $131 \mathrm{~g}(14 \%)$ in men. There were similar, significant differences between preload carbonation levels and between women and men for intakes of carbohydrate, fat and protein (weight and as \% energy), weight of water and weight of fibre (data not shown). There were no significant differences between men and women or beverage preload condition for intakes of beverages (non-carbonated water) at lunch, or between beverage preload condition for reported intakes for the rest of the day (data not shown).

\section{Laboratory evaluations}

The $\mathrm{pH}$ values for the beverages with low, medium and high carbonation were $3.37,3.30$ and 3.25 , respectively. The titration curves were very similar and $100 \mathrm{ml}$ aliquots of the beverages with low, medium and high carbonation required, respectively, 205, 201 and $181 \mathrm{mmol} \mathrm{HCl}$ to bring to $\mathrm{pH} \mathrm{2,}$ and 84,83 and $84 \mathrm{mmol} \mathrm{NaOH}$ to bring to $\mathrm{pH} 10$.

\section{Discussion}

Compared with the beverage with low carbonation, consumption of the beverages with medium and high carbonation led to significantly higher satiety up to the lunch meal $10 \mathrm{~min}$ later, when intakes of food and energy were significantly lower. Overall, satiety ratings increased consistently as carbonation increased from low ( $1.7 \mathrm{vol}$.), to medium ( $2.5 \mathrm{vol}$.), to high (3.7 vol.) and intakes at the lunch meal consumed ad libitum decreased from high, to medium, to low carbonation. Although this is the first study to report effects of dissolved $\mathrm{CO}_{2}$ on shortterm satiety and intakes, a previous study with women and men showed that intakes of a carbonated electrolyte beverage, consumed ad libitum following exercise, decreased significantly and progressively as carbonation increased from 1.1 to 3.0 vol. ${ }^{(10)}$. No gender differences were reported. Other workers, 

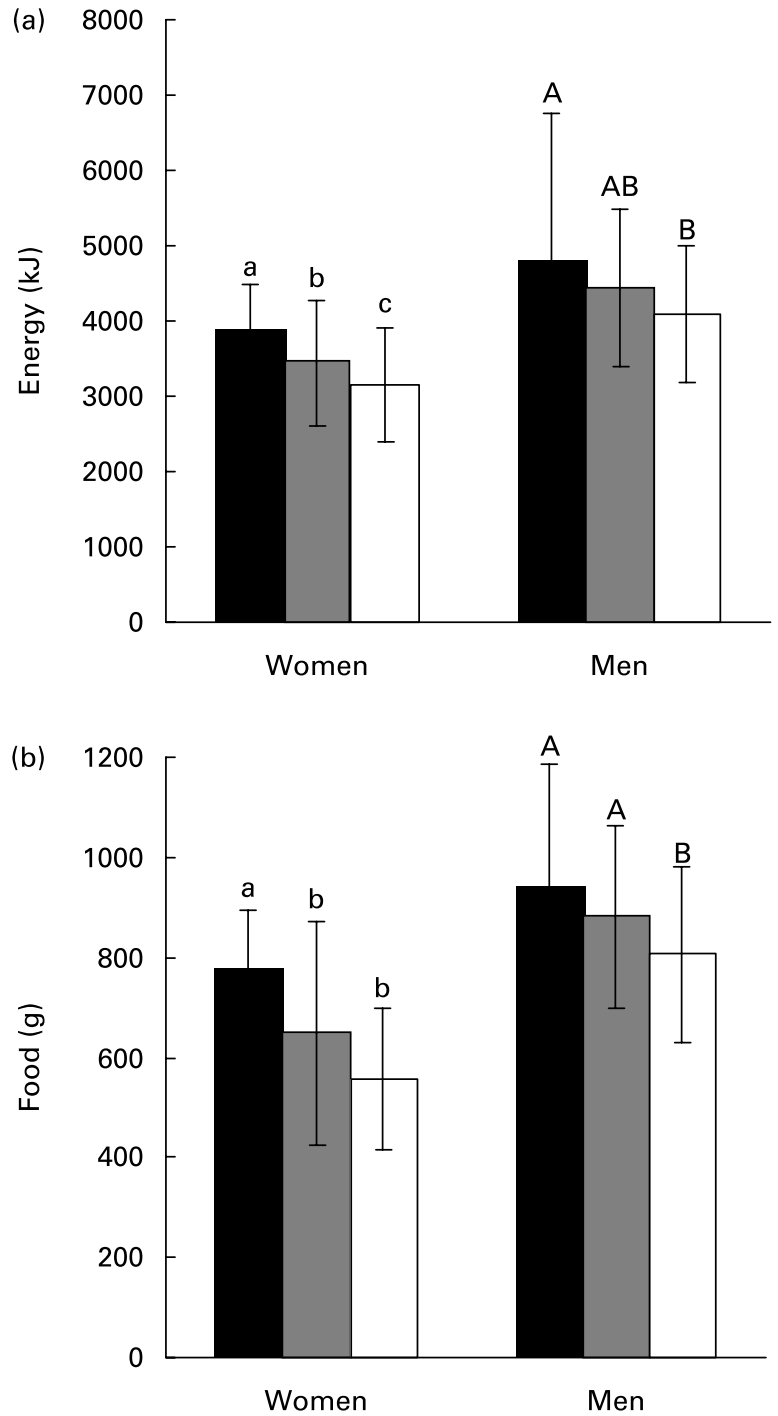

Fig. 3. Intakes of energy and weight of food at a lunch consumed ad libitum $10 \mathrm{~min}$ after a beverage preload with low $(\square)$, medium ( $\square$ ) or high ( $\square$ ) carbonation. Values are means and standard deviations. Columns not sharing a common superscript letter are significantly different $(P<0.05 ; F$ ratio tests); lower case for women; upper case for men. For details of subjects and procedures, see Experimental methods.

who compared the effects of carbonated (2.5 vol.) or still water on satiety and gastric function in women and men, found that satiety was not significantly affected and that gender had no significant effects on gastric emptying, but that carbonated water increased digesta retention in the proximal stomach ${ }^{(9)}$. In the latter study, the water was drunk shortly after a solid and liquid meal and thus the results are not directly comparable with the present study or to previous reports, which have shown that the rate of gastric emptying of solids and liquids is slower in women than men ${ }^{(19-22)}$. However, taken together, the results from the present study and the two previous studies ${ }^{(9,10)}$ suggest that carbonated water can impact on gastric function and increase satiety and that this may be due to increased gastric distension resulting from the liberation of $\mathrm{CO}_{2}$ in the stomach.
Furthermore, these results indicate that $\mathrm{CO}_{2}$ dissolved in beverages can exert effects on satiety and intake similar to that found for gas (air) incorporated into beverages ${ }^{(11)}$. In the latter study, beverage preload volume was increased from $300 \mathrm{ml}$ to $600 \mathrm{ml}$ by the incorporation of air. In the present study, the $400 \mathrm{ml}$ beverages with low, medium and high carbonation contained about 680,1000 and $1480 \mathrm{ml}$ dissolved $\mathrm{CO}_{2}$, respectively. The beverages were consumed under conditions similar to those used for analysis and thus these volumes of dissolved $\mathrm{CO}_{2}$ were imbibed. Although we do not know the amounts of $\mathrm{CO}_{2}$ lost due to effervescence in the mouth before swallowing or subsequently by eructation, the results suggest that a substantial proportion of $\mathrm{CO}_{2}$ reached the stomach and persisted there.

The only sensory or hedonic factor that differed significantly between the beverages was effervescence and this reflected the levels of $\mathrm{CO}_{2}$ present, with subjects rating effervescence very low for the beverage with low carbonation. This indicates that, despite the substantial level of $\mathrm{CO}_{2}$ in the beverage with low carbonation, it was relatively flat. Comfort ratings did not differ significantly from baseline or between beverages, suggesting that the differences in pre-lunch satiety and lunch intakes cannot be attributed to bloating or nausea. Furthermore, the responses to the three beverages for sweetness, flavour, size, pleasantness and thirst were not significantly different, indicating that these factors did not play a role in the observed effects on satiety and intake.

Previous sensory studies that evaluated the effects of carbonation level on sweetness and flavour have yielded conflicting results. Two studies with model sucrose-based systems found that the level of carbonation had no significant effects on perceived sweetness ${ }^{(31,32)}$, while a third study, which combined sucrose and other basic taste stimuli, found that carbonation decreased sweetness perception but had little effect on overall taste intensities ${ }^{(33)}$. In these three previous studies the test beverages were expectorated after tasting. However, in a further study where beverages comprising sucrose, glucose, electrolytes and flavours were consumed ad libitum, sweetness and overall flavour decreased as carbonation level increased ${ }^{(10)}$. Thus, it appears that the relationship between sensory attributes and carbonation is complex and may vary depending on beverage formulation and testing conditions.

Some previous studies that have compared the effects of a range of carbonated and non-carbonated beverages on satiety and subsequent intakes have also assessed effects on thirst. One study showed significantly lower thirst ratings for women following sparkling water or orange juice, compared with regular cola, but there were no significant differences for men ${ }^{(6)}$. A further study with women found that thirst ratings were significantly lower following diet cola compared with orange juice or milk ${ }^{(7)}$. However, in both studies the beverages were consumed with meals and differed in sensory and nutrient characteristics and these factors may have influenced responses. The absence of significant differences in effects on thirst between men and women or between beverage carbonation levels in the present study indicates that, under the conditions tested, level of carbonation had no effects on the ability of beverages to quench thirst.

Increased acidity in foods and beverages has been linked to delayed gastric emptying and to increased satiety ${ }^{(12-15,34)}$. However, $\mathrm{CO}_{2}$ produces a very weak acid in solution and 
the differences in acidity between the beverages in the present study were very small in comparison with the differences tested in previous studies ${ }^{(12-15,34)}$. This further suggests that the effects observed are attributable primarily to the impact of liberated $\mathrm{CO}_{2}$ on gastric distension.

Although the preload design used here does not reflect usual eating patterns, the $400 \mathrm{ml}$ beverages are within the range of regular portion sizes for carbonated beverages in the UK $(330-500 \mathrm{ml})$ and USA $(355-496 \mathrm{ml} ; 12-16$ fluid ounces) ${ }^{(27,35)}$. Thus, the short-term effects observed may be of practical relevance to some eating occasions. Furthermore, it is interesting to note that the differences in lunch energy intakes between the beverages with low and high carbonation, which were $739 \mathrm{~kJ}$ and $710 \mathrm{~kJ}$ for men and women, respectively, were similar to the energy provided by the beverage preload $(639 \mathrm{~kJ})$. This indicates that the effects of higher carbonation may compensate for the energy provided by a beverage preload. Overall, this suggests that it may be appropriate to discriminate between carbonation levels when assessing the potential associations between the consumption of sugar-sweetened beverages and energy intake, weight gain and obesity. However, further work is required to assess whether these effects persist when the time interval between the beverage and the next meal is extended and to compare the effects of dissolved $\mathrm{CO}_{2}$ with those of energy-yielding ingredients such as sugars, which are major components of many carbonated beverages.

\section{Acknowledgements}

This study was funded by a postgraduate award from the Department of Employment and Learning, Northern Ireland (S. A. M.) and by the Northern Ireland Centre for Food and Health, University of Ulster. There were no personal or financial conflicts of interest. A preliminary report of the study was given at the meeting of The Nutrition Society, Dublin, July 2004 (Proc Nutr Soc 63, 84A).

\section{References}

1. Bachman CM, Baranowski T \& Nicklas TA (2006) Is there an association between sweetened beverages and adiposity? Nutr Rev 64, 153-174.

2. Malik VS, Schulze MB \& Hu FB (2006) Intake of sugar-sweetened beverages and weight gain: a systematic review. Am J Clin Nutr 84, 274-288.

3. Pereira M (2006) The possible role of sugar-sweetened beverages in obesity etiology: a review of the evidence. Int J Obes (Lond) $\mathbf{3 0}$, S28-S36.

4. Anderson GH (2006) Sugar-containing beverages and post prandial satiety and food intake. Int J Obes (Lond) 30, S52-S59.

5. Holt SHA, Sandona N \& Brand-Miller JC (2000) The effects of sugar-free $v s$ sugar-rich beverages on feelings of fullness and subsequent food intake. Int J Food Sci Nutr 51, 59-71.

6. Almiron-Roig E \& Drewnowski A (2003) Hunger, thirst, and energy intakes following consumption of caloric beverages. Physiol Behav 79, 767-773.

7. DellaValle DM, Roe LS \& Rolls BJ (2005) Does the consumption of caloric and non-caloric beverages with a meal affect energy intake? Appetite 44, 187-193.

8. Varnam AH \& Sutherland JP (1994) Beverages - Technology, Chemistry and Microbiology. London: Chapman \& Hall.
9. Pouderoux P, Friedman N, Shirazi P, Ringelstein JG \& Keshavarzian A (1997) Effect of carbonated water on gastric emptying and intragastric meal distribution. Dig Dis Sci 42, 34-39.

10. Passe DH, Horn M \& Murray R (1997) The effects of beverage carbonation on sensory responses and voluntary fluid intake following exercise. Int J Sport Nutr 7, 286-297.

11. Rolls BJ, Bell EA \& Waugh BA (2000) Increasing the volume of a food by incorporating air affects satiety in men. Am J Clin Nutr 72, 361-368.

12. Hunt JN \& Knox MT (1972) The slowing of gastric emptying by four strong and three weak acids. J Physiol 222, 187-208.

13. Liljeberg HGM \& Björck IME (1996) Delayed gastric emptying rate as a potential mechanism for lowered glycemia after eating sourdough bread: studies in human and rats using test products with added organic acids or an organic salt. Am J Clin Nutr 64, 886-963.

14. Östman E, Granfeldt Y, Persson L \& Björck IME (2005) Vinegar supplementation lowers glucose and insulin responses and increases satiety after a bread meal in healthy subjects. Eur $J$ Clin Nutr 59, 983-988.

15. Kwapong O \& Fedun-Jacklin V (1995) Hunger Suppressing Foodstuff and Method. United States Patent 5,472,716

16. Rolls BJ, Fedoroff IC \& Guthrie JF (1991) Gender differences in eating behavior and body weight regulation. Health Psychol 10, 133-142.

17. Smeets PAM, de Graaf C, Stafleu A, van Osch MJP, Nievelstein RAJ \& van der Grond J (2006) Effect of satiety on brain activation during chocolate tasting in men and women. Am J Clin Nutr 83, 1297-1305.

18. Mearadji B, Penning C, Vu MK, van der Schaar PJ, van Petersen AS, Kamerling IMC \& Masclee AAM (2001) Influence of gender on proximal gastric motor and sensory function. Am $J$ Gastroenterol 96, 2066-2073.

19. Datz FL, Christian PE \& Moore J (1987) Gender-related differences in gastric emptying. $J$ Nucl Med 28, 1204-1207.

20. Hutson WR, Roehrkasse RL \& Wald A (1989) Influence of gender and menopause on gastric emptying and motility. Gastroenterology 96, $11-17$.

21. Hermansson G \& Sivertsson R (1996) Gender-related differences in gastric emptying rate of solid meals. Dig Dis Sci 41, 1994-1998.

22. Bennink R, Peeters M, Van den Maegdenbergh V, Geypens B, Rutgeerts P, De Roo M \& Mortelmans L (1998) Comparison of total and compartmental gastric emptying and antral motility between healthy men and women. Eur J Nucl Med 25, $1293-1299$.

23. van Strien T, Frijters JER, Bergers GPA \& Defares PB (1986) The Dutch eating behaviour questionnaire (DEBQ) for assessment of restrained, emotional, and external eating behaviour. Int J Eating Disord 5, 295-315.

24. Schofield WN (1985) Predicting basal metabolic rate, new standards and review of previous work. Hum Nutr Clin Nutr 39C, 5-41.

25. Food Standards Agency (2002) McCance and Widdowson's The Composition of Foods, 6th summary ed. Cambridge: Royal Society of Chemistry.

26. Hill AJ \& Blundell JE (1982) Nutrients and behaviour: research strategies for the investigation of taste characteristics, food preferences, hunger sensations and eating patterns in man. J Psychol Res 17, 203-212.

27. Food Standards Agency (2002) Food Portion Sizes. London: The Stationery Office.

28. Caputi A \& Walker DR (1987) Alcoholic beverages, titrimetric determination of carbon dioxide in wine: collaborative study. J Assoc Off Anal Chem 70, 1060-1062.

29. Jones B \& Kenward MG (1989) Design and Analysis of Crossover Trials. London: Chapman \& Hall. 
30. Green SM \& Blundell JE (1996) Effect of fat- and sucrose-containing foods on the size of eating episodes and energy intake in lean dietary restrained and unrestrained females: potential for causing overconsumption. Eur J Clin Nutr 50, 625-635.

31. Cometto-Muniz JE, Garcia-Medina MR, Calvino AM \& Noriega G (1987) Interactions between $\mathrm{CO}_{2}$ oral pungency and taste. Perception 16, 629-640.

32. Yau NJN \& McDaniel MR (1992) Carbonation interactions with sweetness and sourness. J Food Sci 57, 1412-1416.
33. Cowart BJ (1998) The addition of $\mathrm{CO}_{2}$ to traditional taste solutions alters taste quality. Chem Senses 23, 397-402.

34. Lin HC, Doty JE, Reed TJ \& Meyer JH (1990) Inhibition of gastric-emptying by acids depends on $\mathrm{pH}$, titratable acidity, and length of intestine exposed to acid. Am J Physiol 259, G1025-G1030.

35. US Department of Agriculture (2006) Agricultural Research Service. USDA National Nutrient Database for Standard Reference. Release 19. http://www.nal.usda.gov/ 